MATEC Web of Conferences 45, 03003 (2016)

DOI: $10.1051 /$ matecconf/20164503003

(C) Owned by the authors, published by EDP Sciences, 2016

\title{
Performance Evaluation of an Ultra-Lean Combustion Studies in IC Engines
}

\author{
Ravi Kumar Pulii, P Gandhi ${ }^{2}$, K Vijaya Kumar ${ }^{1}$, Damera Babitha ${ }^{3}$ and Manoranjan murthy Kumar Puli ${ }^{4}$ \\ ${ }^{1}$ Dept. of Mechanical Engineering, National Institute of Technology, Warangal, TS-506004, India \\ 2JNTU/MED, Anantapur, A.P-515002, India \\ ${ }^{3}$ JNTU/MED, Hyderabad, TS-500085 India \\ ${ }^{4}$ OU/ MED, Hyderabad, TS-500007 India
}

\begin{abstract}
An investigation was made to determine the effects of ethanol at ultra-lean effective systems utilizing an experimental study. The present study is planned to develop and evaluate the performance, emission and combustion characteristics of the ultra-lean burn Internal Combustion engine was modified to operate on ethanol blends fuels. The study looked at part throttle, constant speed operation of $0 \%, 10 \%$, and $15 \%$ ethanol blends with gasoline mixtures operating in ultra-lean operating systems. In experiment practice the use of homogeneous lean mixtures in engine has been handicapped by several difficulties. The most serious one is that the flame propagation through mixtures becomes gradually slower as the mixture becomes leaner. The mixture distribution in a multi-cylinder engine is a problem because even small variation in mixture ratio on the linear side will strongly effect power output. Enhancement of lean combustion of homogeneous mixtures can be achieved by (i) using ethanol blends with gasoline (ii) using high-ignition energy (iii) providing high compression ratios (iv) creating high swirl in the combustion chamber.
\end{abstract}

\section{Introduction}

Clean, high efficiency combustion technology is one of the most realistic and effective remedies for the current global environmental and energy problems since fossil fuels account for a large proportion of the world's total primary energy resources. Combustion procedure are typically "fast" compared to other types of flow difficulties, requiring only milliseconds for ignition of stationary reactants [1] once adequate energy is provided to allow chemical shifts. In a combustion procedure with a homogeneously mixed reacting flow, the limit ing factor is the reaction rate of the fuel and oxidizer. Reaction rates are a function of specific to the chemical composition and are temperature of the fuel and oxidizer. In particular, lean premixed combustion has attracted much attention for its low emissions of NOx and high energy efficiency [2]. A model study [3], for a packed bed porous burner operates on the principles of a one-dimensional model, including gas-phase transport, solid conduction, interphase heat exchange, and radiation. It is very important to note, the model produced assumes not an is othermal solid, but rather thermal equilibrium between the gas and solid phases. They also assume the solid is only used as a heat recirculation tool and does not influence the chemical reactivity. Based on their research sought to explicitly inspect the validity of mode ling ultralean conditions. In an attempt to reduce fuel consumption and engine-out emissions from s mall air cooled engines, lean burn technology had already existed investigated by small motorcycle engine manufacturers [4-8]. Some of these expertise include use of oxygenated or emulsified fuels, a ir-assisted fuel injection for better atomization of the fuel droplets, and use of catalytic material in the combustion chamber to accelerate combustion. While some technologies may appear overpoweringly expensive for less cost utility engines, they prepare the feasibility of lean operation of small engines. The application of leaner AFRs and a suitable catalytic converter have already been shown to decrease the $\mathrm{CO},\left(\mathrm{HC}+\mathrm{NO}_{\mathrm{x}}\right)$ emissions significantly [9]. Emissions from engine-out are a strong function of fuel supply control, and the best way to achieve accurate fuel quantity metering is by injection fuel. Motorcycle engines have already applied injection fuel over carburetion and now this route is slowly gaining approval with small useful engines.

Because of emergent concerns about performance and emissions, ethanol fuel has received significant attention in the past few years. Ethanol has shown promise as a domestically produced alternative to fossil fuels. This is because it is a liquid simplify ing distribution and has relatively low toxicity. Ethanol has also shown promise in helping to reduce greenhouse gases, especially if the ethanol is produced by cellulosic or sugarcane feed stocks [10-12]. Ethanol fuel has been shown in copious works to offer some significant benefits over gasoline. Ethanol have high octane rating and it gives the ability to operate at higher compression ratios without pre-ignition [13], 
ethanol have greater latent heat of vaporization gives a higher charge density through increased charge cooling [14] and ethanol's higher laminar flame speed and lower flammability limit allows it to be run with leaner, or more dilute, air fuel mixtures [15]. In addition, ethanol fuels generally yield lower criteria pollutant emissions than gasoline [16, 17], lower evaporative emissions due to somewhat lower vapor pressures [18] and when certain renewable feedstock's are used, lower life cycle greenhouse gas emissions [10-12]. Feel strongly that all internal combustion engines control the aggregate of power by controlling the amount of air that is swallowed in the engine, then supplying adequate fuel to efficiently burn. Compression ignition engines allow for an unthrottled operation, and control the aggregate power by varying the amount of fuel metered in the cylinders. Although ultra-lean combustion increases thermal efficiency and decreases emissions, it also typically decreases power output.

\subsection{Applications of an Ultra-lean Combustion}

A large benefit of lean-burn is operating the engine with the throttle more open, and therefore reduced pumping losses. There is another not so widely known benefit and that air is a better gas for transferring work to the piston than exhaust gas alone (thermodynamically to do with the ratio of specific heats at constant pressure and volume). However a large problem with running lean is that there is an excess of $\mathrm{NO}_{\mathrm{x}}$ to $\mathrm{CO}$ (carbon monoxide) and $\mathrm{HC}$ (hydrocarbons). It is not that the engine produces more $\mathrm{NO}_{\mathrm{x}}$ it's just that there is too little $\mathrm{CO} \& \mathrm{HC}$ to reduce the $\mathrm{NO}_{\mathrm{x}}$ in the "three-way" catalyst (this is why it's called a 3-way cat because the 3 major pollutants reduce and oxidize each other). The only company I know using lean-burn gasoline engines at the moment is BMW with their efficient dynamics. On the NEDC test (the fuel consumption and $\mathrm{CO}_{2}$ test quoted by governments and manufacturers) at the very low power points they run lean and then collect the $\mathrm{NO}_{\mathrm{x}}$ in very expensive $\mathrm{NO}_{\mathrm{x}}$ trap catalysts. They then have to regenerate the trap using an excess of fuel to clear the $\mathrm{NO}_{\mathrm{x}}$, preferably when the engine runs rich at high-load. This is probably the way to keep large multi-cylinder engines in the future with ever tightening fuel consumption regulations, because the alternative for reducing fuel consumption is using downsized and down speeded engines running at stoichiometric. The engines designed for lean burning can emp loy higher compression ratios and thus provide better performance, efficient fuel use and low exhaust hydrocarbon emissions than those found in conventional petrol engines. Ultra-lean mixtures with very high air-fuel ratios can only be achieved by Direct Injection engines.

\subsection{Engine Modification}

A single cylinder kirlosker made direct injection diesel engine was chosen to carry out the experiments. This engine was modified to SI engine by incorporating spark plug, ignition system and timing. The experimental study have been accomplished in two stages. In the first stage pure gasoline is used separately in the single cylinder compression ignition modified spark ignition engine. In the second stage, ethanol blends with gasoline are used to determine the performance.

The following modifications are made to the engine for an ultra-lean burn combustion of commercially available gasoline and ethanol with carburetion and spark ignition.

* Thermocouple arrangement is made to measure the temperature of the exhaust gases.

* The squish heights are varied by changing the thickness of the gasket and varying the number of gaskets.

* The fuel injection system is replaced by a carburetor and a spark plug. The spark plug is located in place of the injector with an inclination of $25^{\circ}$ to the vertical.

* Provision for a pressure transducer and intake manifold vacuum tapping are made in the cylinder head.

* Exhaust gas sampling points are provided in the exhaust pipe for emission measurement.

* A selected carburetor jet among the available jets of different sizes is used to operate this engine on ethanolblends with gasoline.

* Ignition system is of conventional low energy 12 $\mathrm{v}$ magnet and coil contact-less system is fitted to the engine, by mounting the coil and magnet on the crank shaft.

\subsection{Approaches for Controlling NOx for Ultra- Lean Combustion}

In an ultra-lean burn engine, adjusting the air/fuel ratio towards the ultra-lean operation side increases the volume of air available for the combustion process. This increases the heat capacity of the mixture and lowers the combustion temperature, resulting in lower $\mathrm{NO}_{\mathrm{x}}$ formation. EGR (whether internal or external) decreases oxygen attention in the combustion chamber by diluting the entering amb ient air with exhaust. During combustion, the lower oxygen content has the effect of dropping flame temperatures, which in turn decreases $\mathrm{NO}_{\mathrm{x}}$ production since the $\mathrm{NO}_{\mathrm{x}}$ production rate is exponentially proportionate to flame temperature.

\subsection{Important Components of the Experimental Setup}

The various components of the experimental setup are detailed below. Fig. 1, gives the schematic diagram of the experimental setup and Preparation of ignition coil and magnet on the diesel engine as shown in Fig. 2. Table 1, gives the specifications of the kirlosker engine. The important components of the systemare
* The engine
* Spark plug
* Dynamometer
* Data acquisition
* Computer 
The exhaust gas analyzer is switched on quite early so that all its systems will get stabilized before the commencement of the experiment. The data length, frequency range to trigger the data acquisition for computer are carefully selected, based on the approximate cycle time of the engine operation, such that there appeared three TDC signals on the display, with the combustion period occupying the center stage.

Table 1. Specifications of kirlosker engine

\begin{tabular}{|c|c|}
\hline No. of cylinders & One \\
\hline Connecting rod length & $230 \mathrm{~mm}$ \\
\hline V $_{\text {disp }}$ & $552.94 \mathrm{cc}$ \\
\hline Stroke & $110 \mathrm{~mm}$ \\
\hline Bore & $80 \mathrm{~mm}$ \\
\hline Rated output & $3.68 \mathrm{~kW}(5 \mathrm{hp})$ \\
\hline Inlet valve opens at & $527^{\circ}$ \\
\hline Inlet valve closes at & $750^{\circ}$ \\
\hline Compression ratio & 12 \\
\hline Exhaust valve opens at & $340^{\circ}$ \\
\hline Exhaust valve closes at & $554^{\circ}$ \\
\hline Speed & $1500 \mathrm{rpm}$ \\
\hline Spark advance & $27^{\circ} \mathrm{BTDC}$ \\
\hline
\end{tabular}

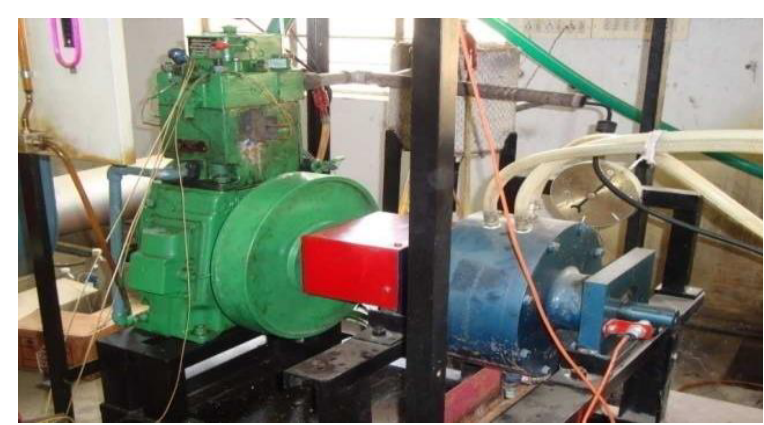

Figure 1. Experimental Set up for Single cylinder Kirlosker diesel engine

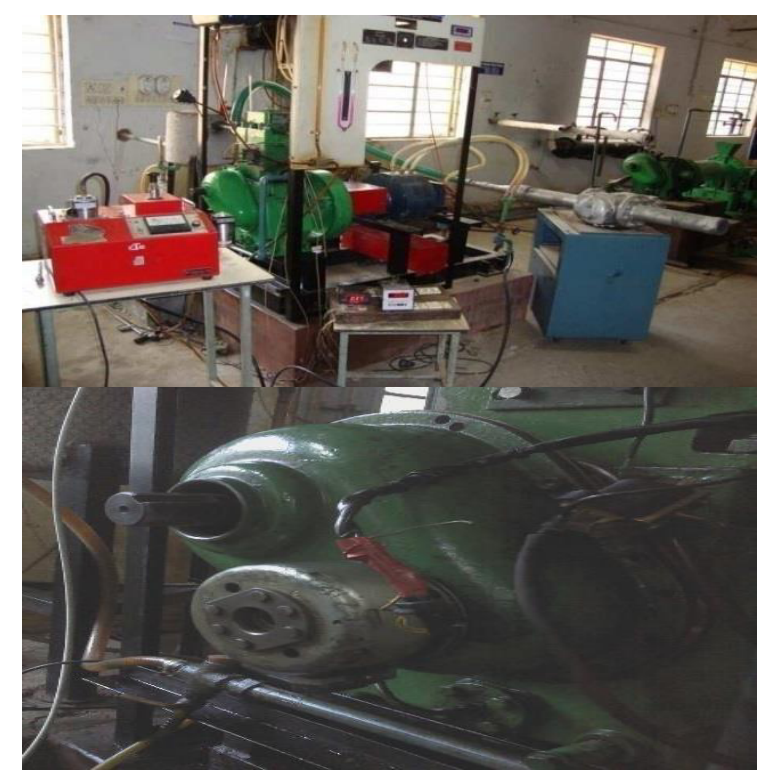

Figure 2. Preparation of ignition coil and magnet on the diesel engine

Ambient condition of pressure and temperature are noted. After the starting of the engine and stabilizing it, air flow, fuel flow, temperature of ambient air, temperature of exhaust gases are noted. The dynamometer readings such as load and speed are also noted. For all the tests the dynamo meter is set on constant speed mode. The pressure and TDC signals are recorded in computer and averaged for 100 consecutive cycles.

The experimental study have been performed in two stages. In the first stage normal gasoline are used separately in the catalytic and non-catalytic combustion chamber with a manifold vacuum of $30 \mathrm{~mm} \mathrm{Hg}$. Then in the second stage, catalytic with a man ifold vacuum of 60 $\mathrm{mm} \mathrm{Hg}$, to ascertain the performance. For all the tests a cyanide bath coated piston with hemi-spherical combustion chamber which has a squish height of 2.4 $\mathrm{mm}$, with a compression ratio of 12:1 used. High energy electronic contact-less ignition system with extended electrode is used. The electrode is centrally located with a deep penetration of $15 \mathrm{~mm}$ into the combustion chamber. The plug is water-cooler to avoid pre-ignition. These techniques are employed based on the test results obtained in the earlier research which are presented.

\section{Results and Discussion}

\subsection{Engine Performance}

Fig. 3 and Fig. 4 gives the variation of indicated power, brake power and brake thermal efficiency respectively. At a given equivalence ratio when percentage of ethanol in the base fuel increases, the power developed also increases. An increase of $10.1 \%$ in the indicated power for $15 \%$ blend is noticed compared to gasoline and $10 \%$ blend respectively.

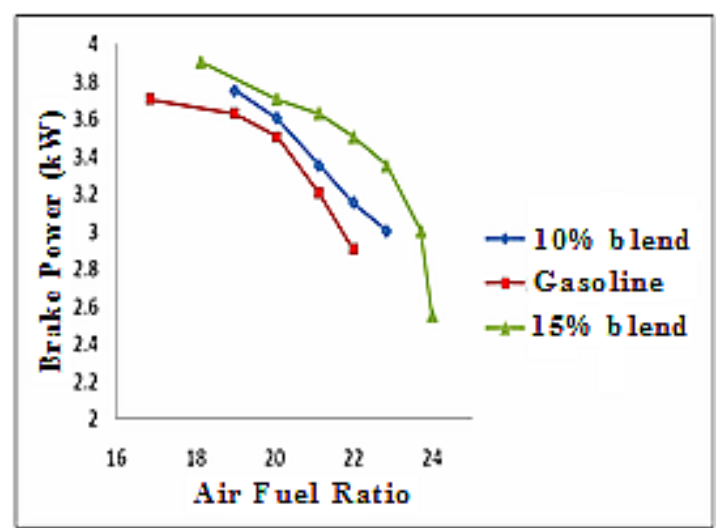

Figure 3. Variation of Brake Power with Air Fuel Ratio

Similarly there is $10.1 \%$ increase in brake power for $15 \%$ blend compared to gasoline and $10 \%$ blend respectively. The brake thermal efficiency is improved by $5.4 \%$ for $15 \%$ blend compared to gas oline and $10 \%$ blend. It is known that, even at the same compression ratio, an engine will have a higher power output and higher efficiency for ethanol blends than operating for gasoline operation. This is due to higher cooling of the charge and faster combustion with ethanol. The variation of brake specific energy consumption (BSEC) in $\mathrm{MJ} / \mathrm{Kg}$ with equivalence ratio can be noticed that the increase of ethanol in the gasoline increases BSEC. This is expected because of the improvement in the combustion process. 


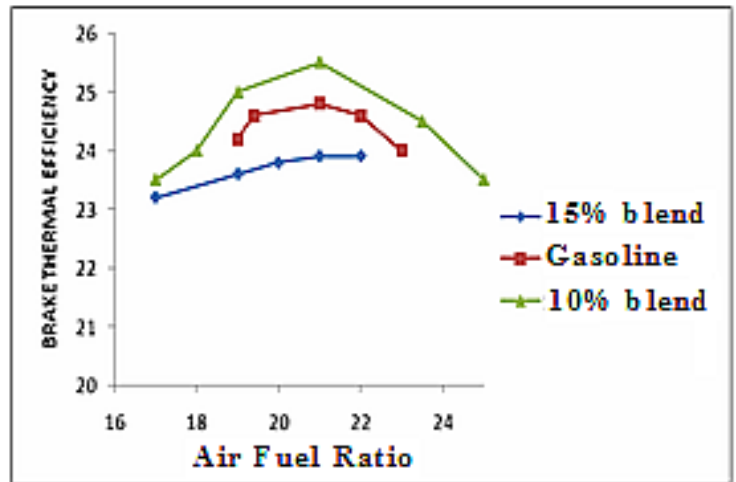

Figure 4. Variation of Brake Thermal Efficiency with Air Fuel Ratio

\subsection{Engine Emissions}

Figures 5, 6, 7 and 8 explain the variations of MBT timing, exhaust temperature, peak pressure, and combustion duration with equivalence ratio respectively. It is noticed that, as the ethanol blend in gasoline decreases, the MBT timing increases. The percentage decrease in MBT timing for $15 \%$ blend are $6.4 \%$ compared to gasoline and $10 \%$ blend. There is no appreciable change in the exhaust temperature between blends and gasoline. The peak pressure is the highest for gasoline and is decreased as the ethanol proportion in gasoline is reduced. This trend again confirms that addition of ethanol enhances the combustion rate. The combustion duration is decreased as the ethanol content in the blend is increased. This is probably due to the enhanced pre-flame reaction.

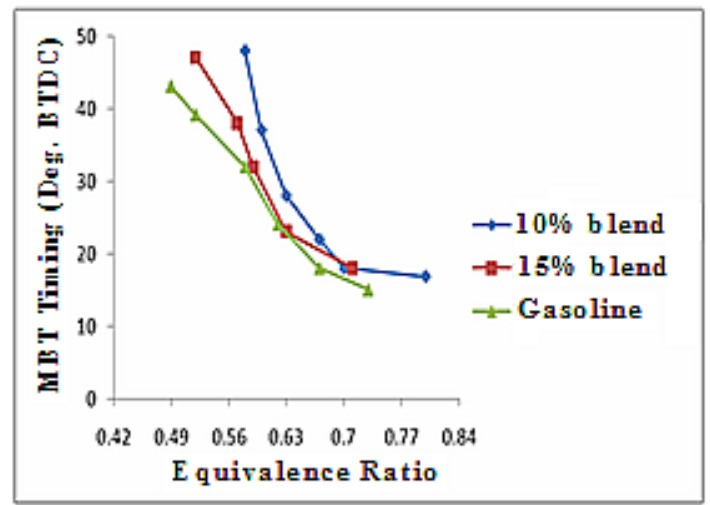

Figure 5. Variation of MBT Timing with Equivalence Ratio

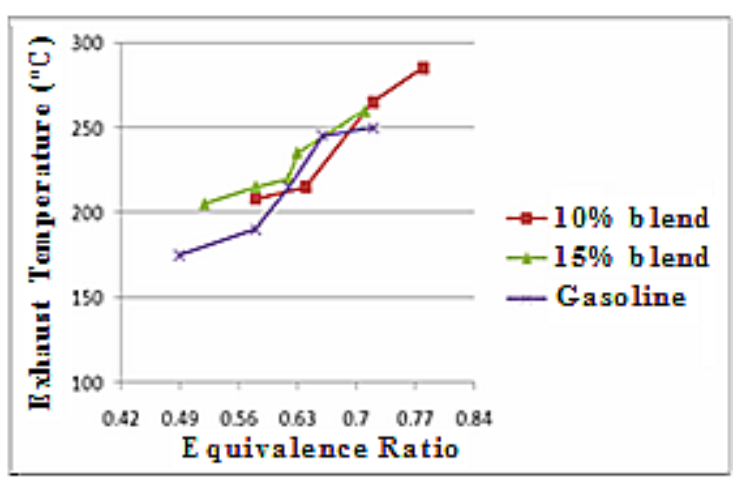

Figure 6. Variation of Exhaust Temparature with Equivalence Ratio

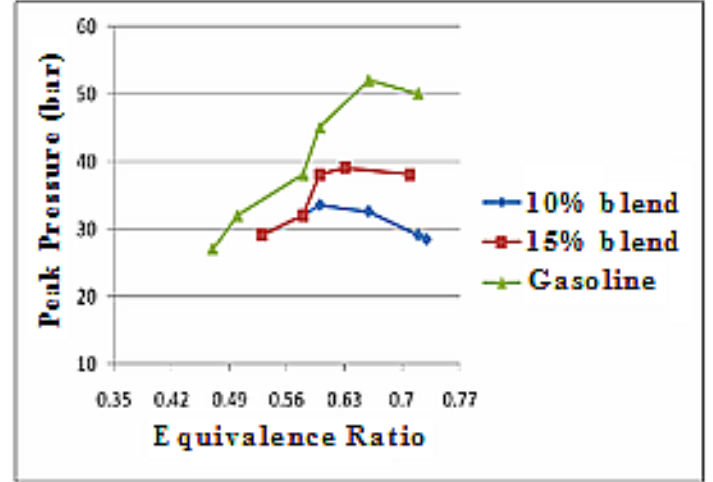

Figure 7. Variation of Peak Pressures with Equivalence Ratio

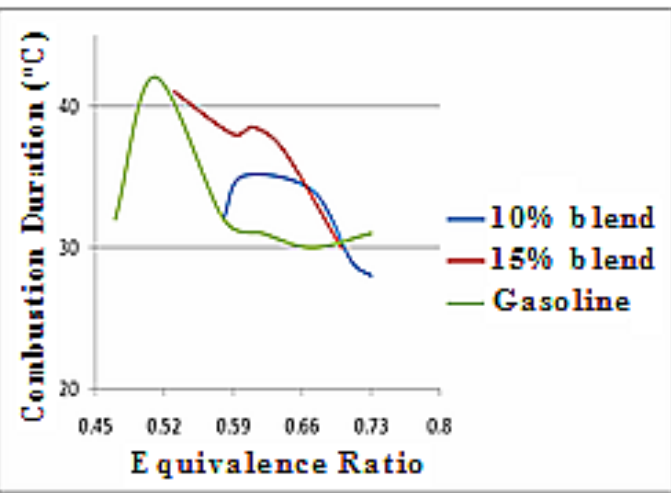

Figure 8. Variation of Combustion Duration with Equivalence Ratio

\section{Conclusion}

Based on the experimental study of an ultra-lean burn combustion the following conclusions have been made:

* Brake power and brake thermal efficiency are higher for ethanol blends compared to gasoline in all the cases.

* Increase of the ethanol proportion in the blend increases power and brake thermal efficiency.

* CO emission is not influenced by higher percentage of ethanol in the blend. $\mathrm{HC}$ emission is found to be reduced with ethanol blends with gasoline.

* Higher swirl increases the heat transfer and hence reduces the efficiency of the engine.

* High energy, high compression ratio with optimum swirl and the use of ethanol blends with gasoline will extend the lean mis fire limit (LML) significantly.

\section{References}

1. Weinrotter Martin, Herbert Kopecek, Martin Tesch, Ernst Wintner, Maximilian Lackner, Franz Winter, Laser ignition of ultra-lean methane/hydrogen/air mixtures at high temperature and pressure. Experimental thermal and fluid science, 2005. 29: 569-577, (2005).

2. D. Dunn-Rankin (Ed.), Lean CombustionTechnology and Control, Academic Press, (2008). 
3. Henneke, M.R. and J.L. Ellzey, Modeling of filtration combustion in a packed bed. Combustion and flame, 117 (4): p. 832-840, (1999).

4. Swamy K, Harne V, Gunjegaonkar D, and Gopalkrishnan K, Study and Development of Lean Burn Systems on Small 4Stroke Gasoline Engines, SAE 200101 1801/4222, (2001).

5. Yoji Fukami, Hisashi Yamashita, Shinichi Tamba, Effect of Lean Burn on Emission Reduction in a Small Utility 4-Stroke Spark Ignition Engine, SAE-978486, 1997-10-27, (1997).

6. Yamamoto Hiroshi, Investigation on Relationship between Thermal Efficiency and NOx Formation in Ultra-Lean Combustion, SAE 1999-01-3328, (1999).

7. Bresenham, Damon, John Reisel, the Effect of High Ethanol Blends on Emissions from Small Utility Engines, SAE 1999-01-3345, (1999).

8. Ishii $\mathrm{W}$, Hanajima $\mathrm{T}$, and Tsuzuku $\mathrm{H}$, Application of Air-Fuel Mixture Injection to Lean-Burn Engines for Small Motorcycles, SAE 2004-32-0052, (2004).

9. Pundir, B. P., Emission Reduction in Small SI Engine Generator Sets, SAE 2004-011089 (2004).

10. Pimentel D, Patzek TW. Ethanol production using corn, switchgrass, and wood; biodiesel production using soybean and sunflower. Nat Resour Res 2005; 14 (1):65-76, (2005).
11. Schmer MR, Vogel KP, Mitchell RB, Perrin RK. Net energy of cellulosic ethanol from switch grass. Tech. rep. United States Department of Agriculture, (2007).

12. Wang M, Saricks C, Santini D. Effects of fuel ethanol use on fuel cycle energy and greenhous e gas emissions. Tech. Rep. ANL-CTR. United States Department of Energy; (1999).

13. Radwan MS. Performance and knock limits of ethanol-gasoline blends in spark-ignited engines, SAE Paper 850213.

14. Dodge LG, Shouse K, Grogan J, Leone DM, Whitney KA, Merritt PM. Development of an ethanol-fueled ultra-low emissions vehicle, SAE Paper 981358.

15. Marinov NM. A detailed chemical kinetic model for high temperature ethanol oxidation. Int $\mathrm{J}$ Chem Kinet, 1999; 31 (3):183-220, (1999).

16. Kelly KJ, Bailey BK, Coburn T, Clark W, Lissiuk P. Federal test procedure emissions test results from ethanol variable fuel vehicle Chevrolet Luminas. SAE Paper 961092.

17. Sinor JE, Bailey BK, Current and potential future performance of ethanol fuels. SAE Paper 930376.

18. Furey RL. Volatility characteristics of gasoline/alcohol and gasoline/ether fuel blends. SAE Paper 852116, 1985. 